\title{
¿Un cronista provinciano? Dos textos desconocidos de Rubén Darío en El Orden de Tucumán
}

\section{A Writer of the Margins? Two Unknown Chronicles of Rubén Darío in El Orden of Tucumán}

\author{
Rodrigo Javier Caresani \\ Universidad Nacional de Hurlingham \\ Universidad Nacional de Tres de Febrero, Argentina \\ rcaresani@untref.edu.ar
}

\section{RESUMEN}

De la mano de los recientes desarrollos teóricos y empíricos sobre el archivo, el campo de la investigación sobre modernismo hispanoamericano experimenta en la actualidad un momento de profunda transformación. La vigencia en los estudios literarios de una "nueva" filología no sólo pone en evidencia los problemas en las ediciones de textos clásicos del fin de siècle, sino que, además, invita a revisar los lugares comunes asociados a dicho movimiento. En estas coordenadas, el caso de Rubén Darío (1867-1916), cuya obra permanece en un estado de notable precariedad, resulta ejemplar. El presente trabajo comenta y recupera dos crónicas desconocidas del nicaragüense publicadas en El Orden, un periódico local de la provincia argentina de Tucumán. Fuera de su indudable valor documental, estos textos de fines de 1898, concebidos en la despedida de su residencia en Buenos Aires, adquieren relevancia si se los enlaza con las preocupaciones que Darío cultivará en su inminente viaje a Europa: por un lado, como un episodio más del "calibanismo" rioplatense; por otro, como anticipación de una perspectiva crítica ante la mitificación del progreso en la Exposición Universal parisina de 1900.

\section{Palabras clave}

Rubén Darío, modernismo, crónica, exposición, prensa rioplatense, filología.

\section{ABSTRACT}

Hand in hand with recent theoretical and empirical developments related to the notion of archive, the field of Spanish American Modernism Studies is currently undergoing a stage of profound transformation. The validity in Literary Studies of a "new" philology not only highlights problems in the editions of classical texts from the fin de siècle period, but also invites researchers to review the clichés asso- 


\title{
Rodrigo Javier Caresani
}

ciated with this movement. In this sense, the case of Rubén Darío (1867-1916), whose texts remain in a state of notable precariousness, is exemplary. This article comments and recovers two unknown chronicles published in El Orden, a local newspaper in the Argentine province of Tucumán, that were written by this author. Besides their evident documental value, these texts, which were conceived at the farewell to his residence in Buenos Aires in 1898, acquire relevance if they are connected to the concerns that Darío will cultivate on his imminent trip to Europe. On one hand, they can be read as yet another episode of Buenosairean "calibanism"; on the other hand, they can be understood as an anticipation of a critical perspective towards the mythification of the concept of progress in the Parisian Universal Exhibition of 1900 .

\section{KEYWORDS}

Rubén Darío, modernismo, chronicle, exhibition, Latin American press, philology.

RECEPCIÓN: 28/06/2020

ACEPTACIÓN: 12/08/2020

\begin{abstract}
A a par de un interés renovado en la filología, que retorna de su exilio como "post-filología" por su nueva y actual condición postpositivista, postdisciplinar, posthistoricista e incluso postmetafísica y postcolonial (Warren, 2003 y 2010), el campo de los estudios sobre el modernismo hispanoamericano experimenta un momento de inflexión signado por el acceso digital - y en buena medida irrestricto - a vastas colecciones de prensa periódica de fines del siglo XIX y principios del xx. En estas condiciones, el análisis de los escritos de Rubén Darío - figura de primer orden en la configuración del movimiento modernista-, pero, sobre todo, el rescate y la recomposición de sus textos cobran una relevancia singular. Comparada con la de sus más significativos contemporáneos — como Julián del Casal, José Martí, José Asunción Silva o Manuel Gutiérrez Nájera, todos favorecidos con proyectos sistemáticos de recolección de sus textos dispersos - la obra dariana se mantiene en un estado de sorprendente precariedad, con una escasa proporción de sus libros editados bajo criterios filológicos, lagunas severas en la datación y localización de las fuentes y la certeza de un caudal considerable de artículos y crónicas perdidos en los abismos de la prensa periódica finisecular. Sin embargo, este diagnóstico compartido por la comunidad académica internacional (Rivas Bravo; De la Fuente Ballesteros y Estévez; Caresani y Link, entre otros) cuenta con una alternativa orientada a modificarlo desde que, en 2016, una universidad argentina, la Universidad Nacional de Tres de Febrero, inaugurara un portal virtual ambicioso (Archivo Rubén Darío Ordenado y Centralizado,
\end{abstract}

104 (an)ecdótica * vol. V, núm. 1, enero-junio 2021 


\section{Dos textos desconocidos de Rubén Darío en El Orden de Tucumán}

AR.DOC), destinado a recopilar cuantiosos y variados materiales darianos repartidos en museos y archivos de todo el mundo - fotografías, manuscritos, artículos en prensa periódica, primeras ediciones, etcétera-, y lanzara una iniciativa de nuevas Obras completas en edición crítica, proyecto este último que publicó su primer volumen a principios de 2020, una nueva edición de La caravana pasa cuidada por el prestigioso filólogo Günther Schmigalle (Darío, 2019).

Con antecedentes que se remontan a las tareas de rescate de Erwin K. Mapes (Darío, 1938), Pedro Luis Barcia (Darío, 1968-1977), Roberto Ibáñez (Darío, 1970) y del mismo Schmigalle (Darío, 2006 y 201 la), las investigaciones de archivo enfocadas en prensa argentina se potenciaron y multiplicaron en el último lustro. No obstante, a pesar de estudios como el concluido por Caresani y Schmigalle en 2017 - que permitió localizar y datar las casi setecientas crónicas publicadas por Darío entre 1889 y 1916 en el diario La Nación, fuente principal de sus colaboraciones en prensa periódica-, numerosos periódicos y revistas de Buenos Aires todavía esperan una revisión exhaustiva y prometen hallazgos de crónicas, artículos y poemas desconocidos. Esto se debe a que el lapso comprendido entre 1893 y 1898, el de la residencia del nicaragüense en la capital porteña, no sólo resulta uno de los más prolíficos, sino, además, aquel en que más dispersa se halla su producción. En efecto, en ese periodo - $-\mathrm{y}$ en el de los meses inmediatos a su partida hacia España - se registran colaboraciones darianas en al menos una veintena de publicaciones fuera de La Nación, sean periódicos o revistas, entre los que se encuentran La Nueva Revista, La Revista de América, La Quincena, Tribuna, La Prensa, La Hoja, El Tiempo, Revista Literaria, El Búcaro Americano, La Biblioteca, El Sud-Americano, Revista Nacional, La Montaña, Atlántida, Caras y Caretas, El Mercurio de América, Instantáneas Argentinas, Artes y Letras, Revista Moderna, Buenos Aires, Argentina, El Sol del Domingo, El Sol, Revue Illustrée du Río de la Plata y La Ilustración Sud-Americana.

Pero si el panorama de los "dispersos" darianos en prensa porteña alberga todavía múltiples enigmas, una situación más radical podría deducirse respecto de sus colaboraciones en publicaciones periódicas de las provincias argentinas. El viaje de Darío en 1896 a Córdoba, la ciudad capital de la provincia en el centro del país, fue objeto de numerosos estudios, pues sus intervenciones en un campo cultural conservador levantaron encendidas polémicas (García Morales, 1998; Boldini, 2016). Aun así, una revisión reciente del periódico local Los Principios logró localizar varios textos correspondientes a esa estadía, entre ellos uno desconocido dedicado al papa León XIII (Barisone, 2017). Un caso parecido, pero más singular, en tanto no se desprende de un viaje cumplido por el nicaragüense, es el que constituyen las dos crónicas publicadas en noviembre de 1898 en el diario El Orden de la provincia de Tucumán, ambas descubiertas en 2014 por Ana María Risco. La investigadora tucumana realizó una completa descripción del contexto de aparición de dichas crónicas, así como de sus núcleos temáticos, pero dejó sin publicar estos "desconocidos", que más adelante 


\section{| Rodrigo Javier Caresani}

se reproducen y anotan. Tal como comenta Risco, El Orden es un periódico local de circulación acotada, fundado en 1883 por Ernesto Colombres (1860-1900), un miembro de la élite político-económica de la provincia - periodista y diputado nacional en 1886, año en que abandona la dirección del diario-, quien recluta a Darío en una de sus estancias en la capital argentina. Por las páginas de El Orden transitan las firmas más prestigiosas tanto locales como nacionales, al punto que en Tucumán "era un honor ser redactor de ese diario" (García Soriano, 1972: 31). Sin embargo, el año 1898 - el de Darío - parece implicar una bisagra para la autoría y la autoridad de la literatura en la publicación:

Luego de la ausencia significativa de publicación de literatura entre 1887 y 1894 [...] comienzan a aparecer gradualmente poemas y cuentos entre 1895 y 1897. Recién en 1898 se reanuda plenamente la actividad literaria en el diario, publicando con mayor regularidad la sección del folletín e incorporando en cada entrega una crónica firmada por alguna personalidad reconocida, ya sea por su labor literaria, ya sea por su trayectoria periodística. La presencia cada vez mayor de escritores-periodistas en sus páginas es un índice de que la cuestión de la especialización tendiente a la futura profesionalización y diferenciación de campos laborales y de especificación del saber dentro del diario comienza a hacerse sentir (Risco, 2014: 371-372).

El miércoles 2 de noviembre de 1898, en la primera columna de la segunda página, un breve párrafo anuncia el desembarco del nicaragüense en las filas de colaboradores del diario y adelanta la noticia sobre la publicación de sus crónicas:

De Rubén Dario

EL ORden incorpora al número de sus elementos intelectuales uno de primera fuerza.

Ruben Dario, el discípulo de Verlaine, el poeta original y fecundo, el literato que tantas caricias de las Musas ha recibido, en su corta y brillante carrera, entra á formar parte de nuestros colaboradores, vertiendo en las columnas de EL Orden, el oro en polvo de su privilegiado intelecto.

Mañana publicaremos la primera carta metropolitana que nos envía.

Recomendaremos su lectura? Para qué! Si Ruben Dario es de los escritores que no necesitan presentaciones ni elogios: es uno de esos intelectuales que se imponen en el campo de las letras y de quien puede decirse que en la literatura argentina su firma representa lo que la rúbrica real en los países monárquicos: todos la acatan.

Nuestros lectores han de agradecernos el nuevo concurso con que se enriquece EL ORDEN, al tener ocasion de deleitarse con las hermosas producciones de uno de los mas escogidos talentos que florecen en el Plata.

La aparición inicial de la firma dariana se consuma al día siguiente, el 3 de noviembre, en un espacio privilegiado de la publicación - la primera página, junto al editorial-, con el título "De Ruben Dario [sic] — (PARA «EL ORDEN»)". Tres 


\section{Dos textos desconocidos de Rubén Darío en El Orden de Tucumán}

semanas después, el sábado 26 de noviembre de 1898, el periódico da a conocer la segunda y última entrega del corpus dariano, con idéntico título y, otra vez, bajo las prerrogativas de realce de la primera página. La crónica se había anunciado, asimismo, en la edición del diario del día anterior, viernes 25 de noviembre:

\section{De Ruben Dario}

Tenemos en nuestro poder una nueva correspondencia de Ruben Dario. Es bella como todo lo que produce aquel privilegiado talento.

La publicaremos mañana.

Quizá el rasgo más llamativo de los anuncios sea la insistencia en la legitimidad estética del corresponsal, quien para 1898 ya había publicado dos de sus libros más influyentes, Los Raros y Prosas profanas. Es factible suponer que, para este momento de la modernización argentina, el proceso de consolidación de una autoridad estética en la esfera pública (Ramos: 1989) se encontrara ya avanzado; y, en efecto, las corresponsalías de Darío para El Orden intervendrán - aunque con una mirada que siempre se reivindica como "literaria" - en la agenda pública más inmediata de la Argentina contemporánea a la escritura. Sin embargo, debería considerarse también la posibilidad de que el periódico evitara referirse a la vasta trayectoria del nicaragüense en la prensa del país - quizá a pedido de él mismo - para no entrar en conflicto con el diario La Nación, que concentraba ya en 1898 el grueso de su producción cronística y empezaba a reclamarle exclusividad.

Las “cartas metropolitanas" que Darío envía a un espacio distante de la modernidad - la periferia de la periferia - se ocupan de los sucesos más recientes en la capital argentina, con una estructura cuya "fragmentación discursiva", para Risco, une de manera aleatoria "diversos tópicos aparentemente no conectados" (Risco, 2014: 373). En rigor, la entropía de los textos encaja con la distribución del fait divers, género del que participa habitualmente la crónica modernista y en el que - tal como explica Roland Barthes - todo ocurre "al nivel de la lectura [...]; sin duración y sin contexto, constituye un ser inmediato, total, que no remite, al menos formalmente, a nada implícito" (Barthes, 2003: 261). Darío expone y calibra el horizonte de expectativas del fait divers en la frase inaugural del primer envío a El Orden. El género relumbra en la temprana advertencia a sus lectores: "Hechos, cosas y hombres, á través de mi impresión, vereis [sic] en estas cartas". Sucesos curiosos, acontecimientos políticos, personajes públicos, artistas conocidos e ignotos se yuxtaponen en un recorrido sin planificación, sin conexiones lógicas previsibles; sin embargo, enlaces subterráneos y silenciosos se van tejiendo al interior de cada crónica y entre las entregas de la serie, los cuales le otorgan una entidad a la causalidad "degenerada", "suspendida entre lo racional y lo desconocido, ofrecida a un asombro fundamental" (Barthes, 2003: 267), característica del fait divers. 
En la primera pieza de la serie, por ejemplo, cuatro nombres propios arman un mosaico de ciertos atributos benéficos para la vida pública en las naciones americanas. La conexión entre estos nombres simula el funcionamiento de un caleidoscopio, pues, al desvanecerse una figura, la siguiente se recompone con algunos de los rasgos de la previa. Del elogio hacia el nuevo presidente que esquiva la guerra e impulsa el progreso - Julio A. Roca, senador por la provincia de Tucumán hasta 1898 - se pasa al panegírico del funcionario probo de mediano rango - Carlos Carlés, un tecnócrata con inclinaciones artísticas, director general de Correos y Telégrafos de 1891 a 1898, diputado por la provincia de Santa Fe desde ese año_- le sigue la valoración del diplomático de carrera - Julio de Arellano y Arróspide, uno de los ministros españoles más experimentados en la política latinoamericana-, para terminar con una loa a Belisario J. Montero, cónsul argentino en Bélgica, quien acaba de publicar un "diario" con ambiciones literarias.

La segunda pieza retoma el eje de la Exposición Nacional, que abría también la primera; trabaja el tópico de las migraciones finiseculares en un contrapunto muy dariano entre lo local - los indios onas arrancados de su tierra por el Estado argentino - y lo universal - los inmigrantes europeos, en este caso italianos-; y concluye, como un espejo de la primera, con una reseña de las novedades artísticas del momento. Antes que suponer que "el autor selecciona subjetiva y arbitrariamente las personalidades de las que se ocupará" (Risco, 2014: 377), quizá convenga considerar en la lectura la potencia del fait divers como un factor de convergencia de fragmentos que se convocan y resignifican los unos a los otros.

En este sentido, las crónicas para El Orden adquieren relevancia en el contexto de los proyectos y las actividades de escritura que Darío cultiva a partir de fines de 1898. Apenas una semana después de la publicación de la segunda y última "carta metropolitana", el 3 de diciembre de 1898, el nicaragüense se embarca desde Buenos Aires con destino a España, como corresponsal de La Nación, para informar del llamado "desastre", la situación de la "madre derrotada" tras la guerra hispano-cubano-norteamericana. En poco más de un año, a fines de abril de 1900, se ocupará extensa y detalladamente de la Exposición Universal celebrada en París, espacio en el que se reafirman sus reparos cada vez más agudos hacia el orden neocolonial, una revisión de su propia francofilia y el paulatino desencanto frente a una modernidad mitificada, pues “al fetichismo del espectáculo opondrá la ironía del estilo, la observación punzante, la desacralización de este vasto mercado, tanto de objetos como de bienes simbólicos, descubriendo las falacias, los colores chillones, la vulgaridad de lo exhibido" (Colombi, 1997: 123). Las crónicas tucumanas de Darío cobran una trascendencia notable porque permiten comprobar que esa perspectiva desacralizante ya se venía ensayando mucho antes del traslado al "otro lado" del Atlántico.

En efecto, la Exposición Nacional de la Industria Argentina - celebrada en Buenos Aires entre el 16 de octubre y el 20 de noviembre de 1898- es el tema central 


\section{Dos textos desconocidos de Rubén Darío en El Orden de Tucumán}

de las correspondencias para El Orden, y Darío somete ese eje, como si anticipara sus recorridos por la Exposición Universal de París en 1900, a un abordaje dialéctico. De un lado, en la primera carta, una exaltación del progreso en compañía de la paz, con metáforas organicistas habituales para la época y un tono idealizante, al borde de la solemnidad; del otro, en la segunda, la contracara de la modernidad en la exhibición humillante de los indios onas, la deslucida "pseudo great attraction de la féria" que el narrador censura en una crítica al voyerismo del exotismo neoimperial. Aunque resulta plausible leer en este contraste una "postura humanitaria - más que indigenista - hacia los pueblos originarios expuestos en la muestra" (Risco, 2014: 382), el recorrido se comprende más cabalmente al situarlo en la estela de una sinuosa posición cosmopolita, cuya legitimidad Darío viene construyendo desde muy temprano en su escritura. Un antecedente memorable de esa posición - y significativo para la lectura de este caso - aparece con fuerza en el soneto "Caupolicán” (incorporado a la segunda edición de $A z u l .$. en 1890), donde la figura de un cacique mapuche local asume en su triunfo "una escala planetaria" (Caresani, 2016: 10) y cancela con esto una larga dicotomía entre civilización y barbarie que humillaba lo autóctono y exigía su exterminio en función del moderno progreso global. Como sugiere Mariano Siskind, el discurso dariano inicia y participa activamente de "una identidad estética cosmopolita y disruptiva, no en el marco de una política cultural particularista, sino como una práctica literaria estratégica que se abre camino a la fuerza hacia el ámbito de lo universal" (Siskind, 2016: 18); esa estrategia involucra un universalismo marginal "desde el que es posible denunciar tanto las estructuras hegemónicas de la exclusión eurocéntrica como la automarginación que resulta del discurso normativo nacionalista" (Siskind, 2016: 18). Ya no se trata, entonces, de la antinomia entre autoctonía y extranjería o entre nacionalismo criollo y universalismo francés - el remanido "galicismo mental" - , sino de una zona exterior a la dicotomía que imagina una salida a la trampa de buena parte del pensamiento americano del siglo XIX. Así como Caupolicán, en su apoteosis, se transforma en un nuevo Atlas - que puede soportar ahora en sus hombros, desde su marginalidad, el mundo moderno-, los onas de la exposición porteña, en su derrota, desde su encierro en el clisé exotista, le devuelven a la modernidad su mirada de desprecio, de arrogancia y de desinterés, pero ya no con una revuelta propia del exilio en la barbarie, sino desde una gestualidad ultramoderna. En la exposición, comenta Darío, "el indio hosco ve á la bella dama que pasa, sin admiración profunda y se diria [sic] sin deseo"; los onas no alteran sus rutinas, pero se aburren y no desean, es decir, están atacados por una de las cualidades modernas por antonomasia, el spleen.

En este punto, las crónicas para El Orden prefiguran esa ironía apenas perceptible que se instala de manera definitiva en los textos sobre la Exposición Universal de París, de modo que, en efecto, la "propia relación [de Darío] con la modernidad 
hab[r]ía estado signada desde siempre por la distancia crítica vivida al mismo tiempo como crisis de la distancia, en otras palabras, por un problema de perspectiva que ahora le permite sustraerse de su dominio y deconstruir la escena representada" (González y Andermann, 2006: 14). Pero, además, es preciso captar el modo en que los textos tucumanos fusionan esa distancia crítica respecto de la manía "exhibitiva" finisecular con una preocupación acuciante en las ambiciones darianas de 1898: el interés por los otros ojos imperiales, amenazantes en la primera crónica para "la América que no habla inglés", los del "boa yankee", que someten el istmo centroamericano "á su insaciable apetito, á sus tragaderas y á su buche, en donde existe la misma soberana pepsina que en el buche fenomenal de su pariente John Bull". Estos términos retoman los de un célebre artículo dariano de ese mismo año, "El triunfo de Calibán" - publicado en el diario El Tiempo de Buenos Aires el 20 de mayo y en El Cojo Ilustrado de Caracas el 1 de octubre-, donde el nicaragüense ya prepara su rotación de la mirada respecto de España e imagina una "Unión latina" ante "esas mandíbulas de boa todavía abiertas" (Darío, 1938: 161). Como bien anota Carlos Jáuregui, los referentes simbólicos de los discursos integrantes del "calibanismo" finisecular "fueron idílicos lugares comunes: la invocación de valores espirituales e idealistas, la latinidad que hacía a América 'hija de España', 'sobrina de Francia' y 'nieta de Roma', y la lengua, que permitía la conexión con el pasado español” (Jáuregui, 1998: 441). Si bien la relevancia desproporcionada del nuevo ministro de España, recién llegado a Buenos Aires, puede leerse en esta clave en el primer texto de la serie - Julio de Arellano y Arróspide aparece como una suerte de redentor aglutinante de la América Central-, es en el segundo donde resalta la fiesta de los italianos en la capital porteña, que Darío aprovecha para celebrar "lo mucho que esa inmigracion [sic] trabajadora y brava ha logrado arraigar el arbol [sic] original y propio en tierra argentina". En un espacio que ya ejecutaba una política de homogeneización y limpieza cultural hacia los migrantes externos - corolario del exterminio de los migrantes internos, por caso, los onas-, estas crónicas darianas sostienen y prosiguen un derrotero que resiste algunos de los binarismos más poderosos del discurso racionalizador moderno.

De este modo, las dos entregas de Darío para El Orden adquieren sentido en el trasfondo de sus trabajos previos, pero, sobre todo, de sus preocupaciones futuras más inmediatas. Al interior de los textos, y a pesar de su estructura dispersa, la yuxtaposición de temas no deja de alentar una lectura que los ilumine mutuamente. Como cronista provinciano, Darío no abandona ni altera su estilo y le exige al lector tucumano competencias que sólo podían adquirirse en la asidua frecuentación de la prensa porteña. Es probable que esta coherencia - entre factores más contingentes, como el requerimiento de exclusividad de La Nación o el viaje al otro lado del Atlántico- haya condicionado una participación de largo aliento en proyectos lejanos a la capital argentina y transformado en efímero su rol de cronista provinciano. 


\section{Nota editorial}

Las transcripciones que se ofrecen aquí provienen del diario El Orden y corresponden a las ediciones del 3 de noviembre de 1898 (p. 1) y del 26 de noviembre de 1898 (p. 1). Para que el lector pueda notar las fricciones que sufren los textos darianos en su pasaje a la letra de molde hemos decidido presentar el texto del diario tal como se encuentra allí, esto es, sin corregir errores o erratas ni modernizar la ortografía o regularizar la puntación. Por un lado, pretendemos que se perciba sin mediaciones el usus scribendi del autor, pero también el descuido a que se someten los textos en su primera circulación, es decir, en el momento de la composición tipográfica del periódico. Por otro, evitamos la normalización que padece el corpus dariano a gran escala, una sistematización que tendió a clausurar y estabilizar los sentidos de sus textos. Todas las intrusiones del editor, reducidas a su mínima expresión, quedan contenidas por corchetes. Empleamos la partícula "sic" en las escasas oportunidades que podrían generar la impresión de una transcripción inexacta (las inconsistencias en la acentuación no se marcan, pues son constantes; pero sí, por ejemplo, las faltas en el nivel de la concordancia gramatical). Las crónicas se acompañan de notas explicativas, cuya extensión limitamos a fin de contribuir a una lectura ágil. 



\section{De Ruben Dario \\ $\left(\right.$ PARA «EL ORDEN») ${ }^{1}$}

Buenos Aires $1^{\circ}$ de Noviembre

Hechos, cosas y hombres, á través de mi impresión, vereis en estas cartas. ${ }^{2}$ Se me encarga la labor de poneros delante de los ojos, en mi prosa, á Buenos Aires, cada diez ó quince dias. Os diré lo que observe en este gran centro, clara y sencillamente, presentándoos mis ideas como ellas vayan apareciendo, aisladas ó en tropel, desnudas ó lujosas. No gusto de la política, pero me acercaré á su morada, veré por entre las cortinas, por las rejas de las ventanas, y os diré lo que mire.

Si hay una pompa social que describiros, ó una general alegria, ó un duelo, estaré pronto. En el arte vivo, en esta metrópoli práctica, y de arte y de literatura[,] de cuando en cuando conversaremos. En fin, á la manera de un amigo lejano que comunica sus sensaciones y las ideas que le sujieren las cosas, los sucesos, las gentes, así seré y mi justo deseo es que mis cartas os sean gratas.

$*$

Mientras la peligrosa probabilidad de la guerra se iba, el general Roca subía á la presidencia de la República. Ya está en su alto puesto. ${ }^{3}$ Buen augurio es ése de que le haya acompañado en su triunfo la paz. Hále tocado, en los primeros dias de su gobierno,

${ }^{1}$ El Orden (San Miguel de Tucumán), 3 de noviembre de 1898, 1.

${ }^{2}$ La fórmula de apertura de la serie y su evidente alusión al género del fait divers se transformará - con ligeras alteraciones - en título de una larga serie de crónicas durante los primeros años de Darío en París. El 10 de abril de 1901 aparece en La Nación el artículo "París - Hombres, hechos e ideas", título que encabezará una secuencia de al menos quince crónicas en el transcurso de los años 1901 y 1902.

${ }^{3}$ Alejo Julio Argentino Roca (1843-1914) fue un militar, político y estadista argentino, nacido en la misma ciudad - San Miguel de Tucumán, capital de la provincia - donde se publica El Orden. Entre 1878 y 1885, ejecutó el programa de relocalización y exterminio de los pueblos originarios en el centro y sur de la Argentina, conocido como "Conquista del desierto". Asumió su segunda presidencia - la referida en la crónica - el 12 de octubre de 1898, en un contexto de tensiones con los gobiernos de Chile y Brasil por la demarcación de límites territoriales. Mitigada la escalada belicista con Chile en las primeras semanas de su gestión, Roca se reuniría con el presidente chileno, Federico Errázuriz Echaurren (1850-1901), el 15 de febrero de 1899, y con el brasileño, Manuel Ferraz de Campos Sales (1841-1913), el 8 de agosto de 1899, para cerrar formalmente los entredichos diplomáticos. 
inaugurar la Exposicion Nacional, fiesta y certámen de fuerza y de ufanía de este país maravilloso, que en momentos en que se sale de la preocupación contenida y molesta de un conflicto probable, da esta muestra de su vitalidad y de su grandeza, manifestando la sávia de su contextura industrial, la sangre poderosa que circula en el cuerpo de la nación. ${ }^{4}$

Es ésta una rica sangre, en verdad.

Hay que mirar cómo en una exposición que en sus comienzos fuera tan combatida, realizada se puede decir, gracias al tesón de unos pocos entusiastas conocedores de la potencia de la república, se ha podido presentar cristalizada y animada esa potencia; de manera que el visitante se queda poseido de una franca admiracion al calcular lo que significa en nuestro progreso este spécimen de la energia argentina, que honra á la América que no habla inglés; pues tal fiesta de Buenos Aires tiene para el observador europeo una proyeccion continental.

La exposición está instalada en la plaza de San Martin, ó del Retiro y abarca el Pabellon, aquel hermoso Pabellon Argentino de la pasada Exposicion de Paris.

De noche, á los fuegos de colores de las iluminaciones, se vé de lejos como un palacio de cuento de Oriente, y no teneis tiempo para hacer reflexiones sobre su propiedad arquitectónica y su oportunidad y ubicacion. La alegria de la luz y lo pintoresco atrayente os vencen y vais á visitar las galerias.

Por lo pronto no cabe en juicio discreto el hacer comparaciones con análogas partes de las grandes exposiciones europeas ó yankees, con las galerías de las exposiciones universales. Ello seria infantil. Pero en su limitada extensión y en su legítimo incremento, la industria propia os admira y os enorgullece. En la galeria de máquinas,

\footnotetext{
${ }^{4}$ La Exposición Nacional de la Industria Argentina se llevó a cabo en la Plaza San Martín, situada en el barrio de Retiro en Buenos Aires, entre el 16 de octubre y el 20 de noviembre de 1898. Al este de la Plaza se encontraba el Pabellón Argentino, una construcción monumental comisionada por el Estado argentino al arquitecto francés Albert Ballu (1849-1939) en ocasión de la Exposición Universal parisina de 1889. Este edificio, sede principal de la Exposición Nacional de 1898, fue desmontado en París en 1890 y reinaugurado en Buenos Aires a principios de 1894. La apertura de la exposición estaba prevista para el 9 de octubre de 1898, pero, como la toma de mando de Roca tendría lugar el 12 de ese mes, fue trasladada a la semana siguiente. Según Ballestero, los diarios de la época señalaron que "el estímulo de las empresas de Ferrocarriles del Sur, Central Argentino, Buenos Aires y Rosario, quienes adjuntaban entradas gratis para aquellos que asistieran a la exposición, facilitará la concurrencia del público, aumentando el número de individuos que pudieron apreciar la gran variedad de elementos exhibidos (La Prensa, 14 oct. 1898). Además de los indígenas [onas] meritorios de observación, se llamaba la atención sobre diversos elementos, como la exhibición de minerales de las provincias de La Rioja, Salta, San Juan y Córdoba, o las distintas máquinas empleadas en la agricultura y la industria que posibilitarán el acercamiento a la 'ciencia' y las maravillas de la naturaleza y la tecnología (La Prensa, 3 oct., 16 oct. 1898)” (Ballestero, 2011: 794-795).
} 
por ejemplo, se vé cómo en pocos años se ha ganado un enorme terreno, á punto de que se encuentra ya en el país la mayor parte de las cosas que antes se importaban necesariamente; y se encuentran de una calidad y baratura que no pueden ser fácilmente vencidas por el trabajo extranjero.

Hacer una descripcion minuciosa de tanta seccion y de las profusas instalaciones de tanta empresa, no es mi propósito, por no cansaros y no cansarme. Pero dejo mi observación: que desde hoy queda constancia de que existe una industria argentina que no se sospechaba, á pesar de los innumerables progresos á la vista; que esta industria es de calidad y cantidad que debe hacer pensar muy seriamente al gobierno de la nacion en facilitar y sostener su curso regular y progresivo; y que, pais que como este cuenta con esas corrientes de vitalidad y de energia, debe procurar mantenerse en la existencia productiva de la paz, sin temor alguno y confiado en la cordura y buen pensamiento de sus hombres dirigentes.

Aún se habla del banquete al doctor Cárlos Carlés. ${ }^{5}$ Cerca de trescientas personas, flor social, se reunieron en esa fiesta, en el Prince George's Hall. Por el hombre público que salía de su puesto despues de haber llenado un deber de trabajo y de honradez en el curso de varios años; por el caballero de carácter, por el amigo firme, por el espí-

\footnotetext{
${ }^{5}$ Carlos Carlés (1866-1925), abogado nacido en la ciudad argentina de Rosario, fue director general de Correos y Telégrafos de Argentina desde 1891 hasta fines de 1898, momento en el que debió renunciar para asumir el cargo de diputado nacional por la provincia de Santa Fe. En su gestión al mando del Correo, publicó los Códigos Postal y Telegráfico (1893), que unificaron la legislación en esos rubros y fueron premiados en la Exposición Postal y Filatélica Universal de Milán en 1894. Con el objeto de lograr una profunda reforma postal que transformara el Correo en un índice del progreso nacional, bajo su impulso se "fundó en 1892 la Escuela Nacional de Ingenieros de Correos y Telégrafos; se adquirió un tesoro para resguardar los valores postales; se inutilizaron las planchas de valores en desuso y se estableció que fuera el Banco Nación el encargado de la recaudación diaria de la renta producida" (Farkas, 2013: 46). En apenas un año, entre 1897 y 1898, Carlés logró reunir una colección de trescientas pinturas remitidas a él por un vasto rango de artistas de su tiempo, la mayoría de los cuales expusieron en el Salón de París. Según explica Farkas, es plausible suponer que Carlés haya enviado pedidos masivos de colaboración a los artistas europeos, quienes realizaron donaciones "con la esperanza de ver sus obras reproducidas en estampillas o postales" (Farkas, 2013: 58). Darío entró en contacto con Carlés a finales de 1895, cuando perdió su cargo diplomático como cónsul general de Colombia en Buenos Aires y, a falta de recursos para subsistir, aceptó acompañarlo — desde el $1^{\circ}$ de enero de 1896 - en calidad de secretario personal. En su autobiografía, Darío dice cumplir "cronométricamente" esas funciones, "las cuales eran contestar una cantidad innumerable de cartas de recomendación que llegaban de todas partes de la República, y luego recibir a un ejército de solicitantes de empleos, que llevaban en persona sus cartas favorables" (Darío, 1915: 203).
} 
ritu noble y transparente que es el doctor Cárlos Carlés, se fué allí á manifestarle que su labor y valor moral son comprendidos, y que siempre, en el mundo de las ideas y de los sentimientos, ese don de los fuertes, la voluntad, es vencedora y saludada á su paso.

Quien escribe estas palabras crée conocer á fondo, y se complace en declarar, que rara vez ha encontrado almas de tan bello oriente engastadas en tan fino acero. Entre los dones suyos no es menor el gusto de la existencia silenciosa del trabajo, exenta de las comunes exhibiciones sonoras. No querria yo que una modestia que aun ni á si misma se reconoce, impidiese la justicia para ese talento laborioso. ¿'Seré indiscreto si digo que en el tiempo en que me ha tocado tener su confianza, he podido ver cuán lisonjeramente ha sido juzgada su cumplida tarea en la Dirección que ha abandonado, por criterios como el del duque de Broglie, Vogüe y sobre todo Alberto Vandal, que han tenido para sus obras postales de codificación y organización, frases que en Europa serian ostentadas por un funcionario como valiosos títulos? ${ }^{6} \mathrm{El}$ Dr. Carlés ha dejado su puesto en medio de las generales simpatías; y las expresiones de aplauso y de alta estima que oyera la noche de esa espontánea y envidiable demostracion, deben haberle satisfecho hondamente.

Acaba de llegar y ser recibido en audiencia pública el nuevo ministro de España, D. Julio de Arellano y Arrospide. ${ }^{7}$ Con tal motivo los diarios han publicado retratos

\footnotetext{
${ }^{6}$ Albert Vandal (1853-1910), historiador y escritor francés, Caballero de la Legión de Honor y miembro de la Academia Francesa desde 1897. Albert, duque de Broglie (1821-1901), historiador y político francés. Dirigió la oposición monárquica bajo la Tercera República. En 1873-1874, bajo la presidencia de Patrice de Mac Mahon (1808-1893), fue ministro del Exterior y luego del Interior. El 20 de febrero de 1862 entró a la Academia Francesa como sucesor de Henri Lacordaire (1802-1861). Melchior, marqués de Vogüé (1829-1916), historiador y arqueólogo francés. El 12 de junio de 1902 ingresó a la Academia como sucesor del duque de Broglie. Darío comentará largamente este acto de homenaje, con glosas del discurso de Vogüé y de la recepción por José María de Heredia (1842-1905), en la crónica "En la Academia" (La Nación, 17 de julio de 1902), incorporada luego al capítulo III del libro tercero de La caravana pasa (Darío: 2019: 163-168).

${ }^{7}$ Julio de Arellano y Arróspide (1846-1909), licenciado en Derecho Civil y Canónico, ingresó a la carrera diplomática española en 1869, y en 1870 se incorporó como secretario a la legación en Berlín. Además de su talento, fue el matrimonio con Margarita Foxá y Calvo de la Puerta (1854-1904) — proveniente de una rica familia habanera y futura marquesa de Casa Calvo - lo que terminó de abrirle camino en la alta sociedad española y, también, en la americana. "En octubre de 1885 obtuvo el nombramiento de ministro residente en Montevideo, tras rechazar poco antes la legación en Caracas, iniciando de este modo un largo periplo de casi veinte años como representante de España ante varias naciones latinoamericanas que le acabó convirtiendo, sin duda, en uno de los diplomáticos españoles más experimentados en
} 
y biografias de este diplomático, que, por otra parte, no es un desconocido en el Rio de la Plata. Es innegablemente un personaje meritorio y cuya larga carrera tiene muy hermosas páginas.

Si escribiese sus memorias, serian interesantísimas como una novela. Digo esto por lo que conozco de su mision entre los presidentes de las repúblicas de la América Central. Los ministros diplomáticos que han estado en Indo China, en Persia, en los lejanos y extraños paises de Oriente, han llenado ya en mucho la curiosidad europea con la narración de sus andares y negociaciones con aquellos príncipes pintorescos; pero una narración semejante relativa á los Ezetas, por ejemplo, de San Salvador, despertaria gran interés. Lo pintoresco, en verdad, no faltaria; la pintura de costumbres poco estudiadas, de políticos y gobiernos imposibles, en unas Américas diminutas, en que caben todas las agitaciones de los imperios bárbaros, reducidas al personal de una opereta; Gengis Khan en Lilipucia; intrigas indescriptibles, embrollos y pompas, semi primitivas; una ausencia absoluta del conocimiento de la vida actual del mundo; la organización administrativa reemplazada por el favor de los militares triunfantes y temidos; el imperio de los advenedizos; la diplomacia y el gobierno á merced de la malicia natural de los caciques; sangre, discursos, doctores en derecho y coroneles; un medio en que lo que sobresale, ó huye, ó se achata, ó se pierde, ó se suicita [sic]. Y sobre todo eso un sol de fuego, el del trópico, y el vaho del boa yankee. Allí, en ese medio, se encontró el señor Arellano en momentos muy tempestuosos. Conoció todas esas figuras que aguardan el sociólogo anatomista que las diseque. Anduvo entre aquellas gentes; evitó por cierto, mas de un hecho atroz, y puso paz entre los jefes mestizos. Concurrió á que Guatemala y El Salvador no se trabasen en otra guerra más, y redactó él mismo las bases del arreglo pacífico. ${ }^{8}$ Por eso entre mis paisanos- porque

esta parte del mundo. Arellano representó sucesivamente los intereses españoles en Uruguay (1885-1888), Guatemala, El Salvador, Costa Rica y Nicaragua (1888-1895), Honduras (18941895), Perú, Ecuador y Bolivia (1895-1898) y, finalmente, Argentina y Paraguay (1898-1903). Un currículum impresionante y además en un momento en que la creciente agitación en Cuba y el inicio de la gran ola migratoria española al Cono Sur colocaban de nuevo a América Latina en primera línea de la política exterior española" (Sánchez, 2016: 247). Según Jorge Eduardo Arellano, Darío "le había dedicado uno de sus artículos: 'Fotografías. Instantáneas diplomáticas' en El Heraldo (núm. 2631, 15 de noviembre, 1891) de San José de Costa Rica, donde lo conoció" (Arellano en Darío, 201 lb: 162). El nicaragüense reconocerá nuevamente al funcionario español en su autobiografía: "En San José pasé una vida grata, aunque de lucha. [...] Colaboré en varios periódicos, uno de ellos dirigido por el poeta Pío Víquez, otro por el cojo Quiroz, hombre temible en política, chispeante y popular, intimé allí con el Ministro español Arellano y cuando nació mi primogénito, como he referido, su esposa, Margarita Foxá, fué la madrina" (Darío, 1915: 109-110).

${ }^{8}$ Arellano y Arróspide presentó sus credenciales al presidente Manuel Lisandro Barillas (1845-1907) para ocupar la legación española en Guatemala — a través de la cual el Ministe- 


\section{Rubén Darío}

ya sabéis, creo, que yo he nacido en Centro América-le estimó mucho la gente de cultura, y fué querido por todos.

Debia el señor Arellano escribir sus memorias. Esa parte de ellas haria todavia conocer muchos detalles de esas revoluciones y danzas de paz y guerra que pasan en paises tan desconocidos aquí como en Europa; y dejaria constancia de sucesos y cosas que mas tarde va á ser difícil reconstruir; digo mas tarde, cuando los Estados Unidos despues de la tajada del Canal, se ingurgiten todo ese istmo rico y tentador, por lo tanto, á su insaciable apetito, á sus tragaderas y á su buche, en donde existe la misma soberana pepsina que en el buche fenomenal de su pariente John Bull.

En letras no tenemos por hoy novedades, fuera del pequeño y fino libro de Belisario J. Montero, que nos ha llegado de Amberes, en donde el autor es cónsul argentino. ${ }^{9}$ Es un libro dandy. Desde su forma eucológica, su impresion impecable y su encuadernacion, hasta la atinada seleccion de las notas que forman ese fragmento de un diario, todo tiene una indiscutible marca de distincion. Esas ideas habitan en buena casa, y me permito recordar que entre los que de ello han tratado, antes de Tristan Klingsor, yo habia demostrado en unos párrafos sobre La casa de las ideas, la correspondencia

rio de Estado español canalizaba sus relaciones con las repúblicas de Guatemala, Nicaragua, Costa Rica y El Salvador - en marzo de 1889. El golpe militar de Carlos Ezeta (1852-1903) en El Salvador, que derrocó al presidente Francisco Menéndez (1830-1890) en junio de 1890, llevó a Guatemala a concentrar tropas en la frontera entre ambos países, pues Menéndez había apoyado los proyectos confederales de Barillas. "La invasión guatemalteca fue rechazada, lo que propició una mediación del cuerpo diplomático acreditado en Centroamérica a petición de Costa Rica y Nicaragua. Arellano tuvo un papel destacado en dichas negociaciones ya que fue elegido por sus colegas para negociar personalmente con los presidentes de Guatemala y El Salvador y para redactar el protocolo que pusiera fin al conflicto, logrando que el presidente salvadoreño retirara sus últimas objeciones al acuerdo de paz tras entrevistarse personalmente con éste en Acajutla en agosto de 1890" (Sánchez, 2016: 250).

${ }^{9}$ El libro de Belisario J. Montero (1857-1929) reseñado por Darío es De mi diario (Bruselas: P. Weissenbruch, impresor del rey, 1898). Luis Berisso (1866-1944), uno de los compañeros de la campaña estética dariana en Buenos Aires, dice sobre el mismo tomo en su reseña de noviembre de 1898 para El Mercurio de América: "En medio de la desoladora aridez de nuestro ambiente de mercaderes y agiotistas, la aparición de un libro artístico es como una ráfaga de aire fresco, en estos días de bochorno" (Berisso, 1898: 265). Sobre el vínculo entre Darío y Montero, Teodosio Fernández apunta que "se había iniciado en Buenos Aires", y agrega: "La amistad era estrecha, según parece confirmar algún otro documento de la AEciD: Ezequiel Soria, que por entonces se preocupaba por la modernización del teatro argentino, buscó la recomendación de Darío ante Montero cuando pretendía viajar a Bélgica, según puede verse en una carta suya fechada el 6 de diciembre de 1902" (Fernández, 2017: 224). 
que hay entre éstas y sus habitaciones. ${ }^{10}$ Montero ha regalado un lindo chalet á sus señoritas mentales. Ha hecho bien; y Lugones, que, con todo lo que sabeis, es un excelente monstruo y usa en veces maneras de buen gigante, se ha detenido á admirar ese encanto de la forma. Las ideas le han visto á través de las ventanas, y se han ocultado al ver la piel que llevaba, y al sentir su olor, el olor fauve. En todo caso, yo les aconsejo que se acostumbren mejor á estas exhalaciones conocidas de las estinfálidas y no á los patchulies es en boga, ó á las aguas floridas de la crítica profesora.

Este librito me agrada por virtud de decir el autor lo que siente y lo que sabe, de manera no vulgar, lo que ya es un triunfo. Recordando que la obra es un diario, y que por lo tanto necesita el pensamiento concentracion y desnudez, el mérito adquiere mayores proporciones. Desde luego el sentido del arte sobresale. Hay observaciones de Montero que creeria uno leerlas en una pájina de Maurice Barres. Pasa de cuando en cuando un soplo stendhaliano, y en general se diría que el escritor argentino ha hecho por sutil diletantismo aprovechados estudios de auto-floricultura. El yo es planta difícil de cultivo, y es mucho lograr coger, así sea la estación propicia, una sana y olorosa flor, un fruto maduro.

El gran Barbey d'Aureville [sic] nótase tambien por su influencia, lo cual no es de extrañar en esta obra de daudismo [sic]. Hace bien Montero en amar aquella noble sombra. Gustar de Barbey es desde luego una señal de superioridad intelectual y de gentileza de espíritu.

En la galeria nobiliaria de la literatura se destacará siempre el retrato de aquel duque del estilo, en cuya escritura se ven siempre junto al pensamiento damasquino ó toledano, la empuñadura de oro y los puños de encaje.

RUBÉN DARÍO

${ }^{10}$ En la crónica "Las casas de las ideas", publicada por primera vez en febrero de 1896 en la Revue Illustrée du Rio de la Plata (luego incorporada al tomo Letras de 1911), Darío escribe: "Así, pues, las ideas, con sus carnes de palabra, vivientes, activas, se congregan, hacen sus ciudades, tienen sus casas. La ciudad es la biblioteca; la casa es el libro" (Darío, 1938: 83). 



\section{De Ruben Dario}

\section{(PARa EL ORDEN $)^{1}$}

Buenos Aires, 20 Nov. 98

Ya estareis al tanto de las discusiones y encuentro de juicios, cálculos y profecías que ha producido el alza rápida del papel; quienes á pesar de reconocer el peligro, opinando que ello es de enseñanza que no necesita demostracion, por dar tal movimiento económico una medida de la fé que existe en la vitalidad del pais, como en la base de responsabilidad gubernamental; quienes mirando en el descenso del metálico una perturbacion en los asuntos comerciales y un daño inmediato á las industrias. El rápido desequilibrio está á la vista y las consecuencias no se han hecho aguardar. La solucion de la emergencia estaría en que los hombres de gobierno pusiesen los medios necesarios para aminorar, lo que desde un principio se ha mostrado de sumo peligro para los intereses de gran parte de la comunidad, dado que se corre el riesgo de que el estado actual se prolongue, con pérdidas seguras para las empresas industriales y el comercio importador é interno. ${ }^{2}$

Hace pocos dias he ido á ver los sonados indios onas que están exhibiéndose en la Exposicion Nacional. ${ }^{3}$ ¿Hasta qué punto existe el derecho, en el hombre civilizado, de

${ }^{1}$ El Orden (San Miguel de Tucumán), 26 de noviembre de 1898, 1.

${ }^{2}$ No se trata, en este caso, de un "conflicto del papel" en tanto insumo para la prensa, que justificaría "las opiniones de Darío sobre la política económica del país" (Risco, 2014: 381). En rigor, la crónica se refiere a la valorización del papel moneda en Argentina, factor que había llevado a un proceso inflacionario acelerado, a la pérdida de competitividad de la producción nacional y a la falta de solvencia del sistema financiero. En respuesta a estos fenómenos, la administración de Roca, a través de Carlos Pellegrini (1846-1906), logró sancionar en 1899 la Ley de Conversión 3871, que habilitaría una fuerte expansión económica en las décadas siguientes.

${ }^{3}$ Ballestero puntualiza que la Exposición Nacional de 1898 incluyó "la presencia de indígenas vivos: dos familias fueguinas, tal cual se leía en los principales diarios de la época, traídas por el gobernador de Tierra del Fuego, teniente coronel Pedro Godoy. En este caso [se trataba ...] de un grupo de personas nombrado como onas, expuestos durante un mes en la Sección Femenina de la Exposición Nacional, siendo posible observarlos en su vida cotidiana. Presidida por Teodolina de Lezica de Alvear (1876-1967), hija de Luis Ricardo de Lezica Thompson y Teodelina de Alvear Fernández Coronel, la Sección Femenina se emplazaba en 
aprisionar como un simple babuino á un semejante en estado más ó menos primitivo y hacerle objeto de la pública curiosidad, ó del público divertimiento? Allí están los indios azorados, nostálgicos de su existencia libre, de su aire y de su vision del mar del Sur; están envueltos en sus pieles, con sus hijos y sus perros; miran á las gentes que les contemplan ya con indiferencia, ya con un asombro igual y recíproco; no rien, se diría que no saben reir; les caen las greñas oscuras y lacias por los hombros; un indio zahareño se acurruca, al lado de sus flechas, y clava en quien le observa una mirada que es una flecha negra; una indiecita de quince años tiene desnudas las piernas finas y los pies de señorita salvaje, pulidos por el pedicuro de la naturaleza, chicos y monos, treinta veces mas lindos que su cara; un indiecito boquiabierto, está fraternalmente al lado del perro, que él sí, se diría lleno de una rara y vivaz inteligencia.

Está allí el grupo, como incómodo entre esos ruidos de las máquinas y esos sones de las músicas y ese ir y venir de los hombres civilizados. Y el indio hosco ve á la bella dama que pasa, sin admiración profunda y se diria sin deseo; á lo más, esa maravilla blanca y rosa, le llamará la atencion por sus sedas y joyas, su [sic] sombreros de pájaros y flores, sus sombrillas lila ó clavel, á la luz del flamante verano. Estos pobres seres traidos de las costas del Sur, no tienen aqui, ciertamente, atractivo alguno, como no sea el de ejemplares de jardin de aclimatacion; y esa indiecita chica de los pequeños piés, no creo que sea en nada comparable á la jóven pampa Lokoma, que hoy es castellana y condesa en Francia. ${ }^{4}$ Recientemente en su habitáculo de la Exposicion, la Ona de quince años ha cometido la inconveniencia de parir un robusto y sano muchacho, lo cual ha puesto una nota más en la pseudo great attraction de la féria.

la parte superior del Pabellón Argentino. [...] Destacaba el diario La Prensa la variedad de elementos que podían hallarse en esta sección, con vitrinas dedicadas a asilos y casas de pobres, compartiendo espacio con tejidos, bordados y telas" (Ballestero, 2011: 794).

${ }^{4}$ Lokoma (1874-1910) fue una niña de un pueblo originario adoptada en 1879 por el conde y la condesa Amelot de Chaillou, cuando el conde cumplía funciones diplomáticas para Francia en Buenos Aires. Según indica Risco, es probable que la mención dariana tenga como antecedente el "Viaje al Río de la Plata. Tres meses de vacaciones de Emilio H. Daireaux, publicado por entregas en La Ilustración. Revista de Hispano-América (Barcelona) a lo largo de aproximadamente un año, entre el 23 de octubre de 1887 y el 16 de octubre de 1888. En dicho texto, Daireaux relata, en el número 400 de la revista, una de las famosas campañas al desierto, la que involucra la 'Zanja de Alsina', antes de la agresiva 'Conquista del Desierto' [...]. El Estado argentino decide trasladar a los sobrevivientes a Buenos Aires y, como no puede hacerse cargo de tanta cantidad de gente, se decide entregar las mujeres y niños a los ciudadanos interesados en recibirlos como criados. La joven Lokoma, según relata Daireaux, fue adoptada y criada por la Condesa de Amelot de Chaillou, cuyo esposo era representante de Francia en Buenos Aires en esa época. Daireaux señala el ejemplo exitoso de esta jovencita para contrarrestar el determinismo de los antropólogos cientificistas que condenan como inferiores a los nativos de América” (Risco, 2014: 385). 
En lo cual, repito, no existe un verdadero atractivo. No os imagineis ni danzas bárbaras, ni cosas de llamar la atencion por su lado pintoresco ó por su rareza. Son unos tristes ejemplares del animal humano de nuestras costas, envueltos en sus quillangos, y con aires justamente aburridos; nada más.

Con la luz del dia, el de la colocacion de la piedra fundamental del monumento que ha de elevarse en honor de Garibaldi, la capital vió despertarse un rumor de fiesta. ${ }^{5}$ Basta pensar en la cantidad y variedad del elemento italiano en Buenos Aires, para que se suponga lo que sería en horas dedicadas á conmemorar al héroe preferido. Pero hay que ver el fervor patriótico y el entusiasmo comunicativo de estas gentes de Italia, sus procesiones de sociedades líricas, gremiales o patrióticas; la alegria solemne y musical de sus desfiles con sus estandartes de oros y sedas, para comprender lo mucho que esa inmigracion trabajadora y brava ha logrado arraigar el arbol original y propio en tierra argentina, y al mismo tiempo hay que observar las demostraciones de afecto á la tierra que les hospeda, y cómo han logrado unir en su sentimiento el pais de la cuna y de la sangre con el nuevo á que han venido en obra de labor, de paz y de fraternidad.

En cuanto á la estátua de Garibaldi en Buenos Aires, he aqui como he resumido mi pensamiento, sobre quién fué el hombre de la Camisa Roja:-

De los hombres que, muy cercanos, han sido envueltos en el vapor de la leyenda: el que puso siempre en su obra, en su indumentaria, en su isla, fantasia. Pasa por los versos de Hugo, en la memoria de sus contemporáneos, en las mil formas del retrato, de la estátua, de la invencion del pintor de batallas, invariable, frente descubierta ó cabeza bajo el gorro griego, inconfundible: y á su evocación, es el despertar de una poesia de héroe antiguo en nuestra vida secular. Comprendo y es de justicia mental, que á ciertas almas repugne lo que en el tipo dominador existe, de tonante, de lo que se podría llamar la retórica de la accion; más es de recordar que[,] principalmente, ello constituye la característica de quien pudiera ser un specimen representativo su-

\footnotetext{
${ }^{5}$ El 6 de noviembre de 1898 se colocaba en Buenos Aires - en la llamada, desde ese momento, Plaza Italia - la piedra fundamental de un monumento conmemorativo a Giuseppe Garibaldi (1807-1882), que recién sería inaugurado varios años después, en junio de 1904. En el número de una revista porteña correspondiente a noviembre de 1898, Darío había publicado un texto breve relativo a este acontecimiento, titulado "El hombre de la camisa roja" (El Mercurio de América, año I, tomo I, número 5, noviembre de 1898, 304). La cita del propio Darío que se recoge en el párrafo siguiente y va hasta el final de este apartado de la crónica reproduce palabra por palabra y en su totalidad el texto de El Mercurio de América (véase Darío, 1938: 163-164).
} 
perior del latino. Ha puesto, no hay duda, una verja erizada, ante los que buscan otra cosa que los sufragios sectarios, la marca de vulgar admiracion, discursos mandiles - y la figura erigida, valor, consagracion á una bizarra caballeria internacional;- Garibaldi, un romántico, alma hermana de Byron.

En Buenos Aires, su estatua cristalizará una justicia; en el Rio de la Plata, [ं]no fué acaso, su odisea gaucha, tan brillante, como por ejemplo, la toma de la bandera del enemigo de Francia, ó Marsala, ó Volturno? La juventud intelectual argentina, sobre la preocupacion incidental de una lucha entre heterodoxos y ultramontanos, verá siempre, en el hombre de la Camisa Roja, en su efigie monumental saludada por el sol de Mayo, un alto, poético y generoso símbolo.

En el pequeño mundo metropolitano hay algun movimiento.

Se prepara el salon de la Exposicion Nacional, en donde se anuncia habrá más de una novedad interesante; por lo pronto Cárcova, que vá en la delantera de nuestro movimiento artístico, presentará una obra de alto valor pictórico y que simboliza una bella y dolorosa señal social. El autor de esa violenta y valiosa tela que se pudo admirar en años anteriores, Sin pan y sin trabajo, prosigue poniendo al servicio de un noble ideal de humanidad su potente y generoso talento. ${ }^{6}$

En el Ateneo, la Exposicion Collivadino atrae á los curiosos, profesionales y aficionados. Es Collivadino un jóven de esta República que ha permanecido en Roma en una vida estudiosa y de labor. ${ }^{7}$ Allá ha sabido impregnarse de esa luz amable que

${ }^{6}$ Ernesto de la Cárcova (1866-1927) había presentado en 1894 — para la segunda Exposición del Ateneo de Buenos Aires - Sin pan y sin trabajo, obra que lo ubicará entre las figuras centrales del arte nacional en Argentina. Entre varias menciones esporádicas, el nicaragüense le dedica una extensa crónica ("Artistas argentinos - De la Cárcova") publicada en el diario porteño El Tiempo el 25 de junio de 1896 (Darío, 1938: 111-113). Allí Darío escribe que "probada está su calidad por la resistencia y la continuación de su labor, en viaje a un ideal en medio de las turbas de mercaderes, de los cenáculos prácticos, de las victorias del yankismo, en la magnífica ciudad de Buenos Aires, la más grande de lengua castellana" (Darío, 1938: 111). Por su parte, el pintor ilustró la primera versión del "Responso" con que Darío homenajea a Verlaine, aparecido en la revista Argentina, número 10, el 15 de enero de 1896.

${ }^{7}$ Pío Collivadino (1869-1945), pintor, grabador y escenógrafo argentino, director de la Academia Nacional de Bellas Artes entre 1908 y 1936. Asistió al Reale Istituto di Belle Arti de Roma durante seis años, donde se graduó de Pittore artista en 1898. Ese año regresó por primera vez a Buenos Aires desde su salida a Italia y, en noviembre, presentó su primera exposición individual en los salones del Ateneo porteño. Allí exhibe, entre otras obras, las copias de los frescos de la Basílica de San Lorenzo al Verano de Roma, muy comentadas por la prensa de la época, y los óleos Vía Appia - que obsequia al presidente Roca-, Interior de un templo y la fotografia de un cuadro en preparación, Caín, que quedaría inconcluso.

124 (an)ecdótica * vol. V, núm. 1, enero-junio 2021 
ayuda en sus trabajos á la concepcion de la idea gráfica; y aunque en lo que aquí presenta no se vé sino la gimnasia de quien se ejercita para pasos superiores, revela que hay en quien tal ejecuta, metal de buena ley. Son manchitas, paisajes esbozados, cabezas de estudio, rincones de iglesia; unas telas insinúan dotes de observacion y de color, y una frescura y seguridad que afirman la sangre del artista nacido.

No se presenta como maestro, sinó que trae unas cuantas muestras de laborioso y de amante de su arte preferido. Una fotografia hay de un carton en que el asunto es la tradicion de Caín. No se puede menos que admirar la figura bien ideada y bien tratada, de una fuerza nada común y que autentica un don de poesía y de altura mental. Entiendo que lo mejor de Collivadino son sus frescos, hechos allí en Italia.

El escultor ruso Michel Kaplan está de paso entre nosotros. ${ }^{8}$ Es un simpático tipo de artista, que ha venido á dar un paseo por estas tierras, para él nuevas y extrañas.

Reside en París, desde donde ha enviado buenas obras á Rusia, como el busto del escritor Belinski, que adorna una de las plazas de la ciudad de Penza. Aquí hará algunas pocas obras, para dejar huella de su paso. Este hombre modesto y de un mérito indiscutible, contrasta con los artistas que hacen el commis voyageur de sí propios, en excursiones sonoras de dentistas, en busca de un público novelero que les llene la hucha. Lo mismo que de Kaplan diré de Achille de Dominice, notable pintor romano que visita Buenos Aires desde hace algunos dias. ${ }^{9}$ No oireis sones de bombo y timbales á su alrededor; pero si veis sus acuarelas ricas de luz, sus telas de fiestas de colores, sus paisajes de la campiña romana, sus obras para inteligentes, de un dibujo siempre impe-

${ }^{8}$ Un breve artículo aparecido el 24 de octubre de 1897, con la firma de A. Juvé de Buloix, en La Revue Diplomatique de París ("Écrivains et artistes russes. V. G. Belinsky et Michel Kaplan", año 19, número 43, 10) da noticia de la llegada del joven escultor ruso a la École nationale des Beaux-Arts. Según comenta la crónica, Michel Kaplan se perfecciona bajo la tutela de Horace Daillon (1854-1946), mientras concurre al taller del célebre Alexandre Falguière (1831-1900). Entre algunos bustos y medallas, obras ya realizadas, el ruso proyecta honrar el cincuentenario de la muerte de Vissarion Grigoryevich Belinsky (1811-1848) con un gran monumento. Curiosamente, entre las "obras" de Kaplan en Argentina figura un artículo para El Mercurio de América, "Impresiones artísticas", publicado en el número de diciembre de 1898, donde el escultor muestra su sorpresa ante "la inmensa ciudad de Buenos Aires, cosmopolita por excelencia" (Kaplan, 1898: 331), comenta las obras de Schiaffino, Sívori, Della Valle y De la Cárcova reunidas en la Exposición Nacional y se refiere al propio Darío como "el cincelador sin rival de la frase, el Verlaine de Buenos Aires, en el alma como en la fisonomía" (Kaplan, 1898: 332).

${ }_{9}^{9}$ Achille de Dominicis (1851-1917), pintor de género y experto en acuarela, nació en Tívoli y se educó en la Accademia di Belle Arti de Roma bajo la tutela de Filippo Prosperi (18311913). Desde 1881 formó parte de la Società degli Acquerellisti en Roma, donde ocupó, además, el rol de tesorero. Su obra más reputada y reproducida es "Il bersagliere e la cantiniera" (véase Gubernatis, 1889: 164). A pesar de la promesa de un futuro artículo sobre el pintor romano, Darío no volverá a referirse a De Dominicis. 


\section{† Rubén Darío}

cable y magistral, pues es la cualidad principal suya, confesareis su eminencia en esas armoniosas disciplinas. He de escribir en breve un estudio sobre este singular tipo de artista, y allí diré largamente lo que me ha hecho pensar su produccion sobre el arte actual de Italia, y otros puntos con ello en relación.

RUBÉN DARÍO 


\section{Dos textos desconocidos de Rubén Darío en El Orden de Tucumán}

\section{Bibliografía}

Ballestero, Diego A.

'Los 'fueguinos', Robert Lehmann-Nitsche y el estudio de los onas en la Exposición Nacional de Buenos Aires (1898)", en História, Ciências, Saúde-Manguinhos. Río de Janeiro, volumen 18, número 3 (2011), 789-810.

Barisone, José Alberto

"Un artículo de Rubén Darío, 'León XIII', publicado en el diario Los Principios de la ciudad de Córdoba (Argentina)", en Letras. Buenos Aires: Universidad Católica Argentina, Facultad de Filosofía y Letras, número 76 (2017), 145-149.

BARTHEs, Roland

"Estructura del suceso [fait divers]", en Roland Barthes, Ensayos críticos. Buenos Aires: Seix Barral, 2003, 259-272.

Berisso, Luis

"De mi Diario", en El Mercurio de América. Buenos Aires, año I, tomo I, número 5 (1898), 265-268.

Boldini, María Gabriela

“La 'reinvención' del modernismo en Córdoba: sus protagonistas y proyecciones", en $R E$ CIAL. Córdoba: Universidad Nacional de Córdoba, Facultad de Filosofía y Humanidades, volumen 7, número 10 (2016), 121-142.

Caresani, Rodrigo

"El salvaje cosmopolita: dilemas de la modernidad en Rubén Darío", en RECIAL. Córdoba: Universidad Nacional de Córdoba, Facultad de Filosofía y Humanidades, volumen 7, número 10 (2016), 6-19.

Caresani, Rodrigo y Daniel Link

"Saberes del archivo en la era de la reproductibilidad digital: un prototipo para Rubén Darío", en Virtualis. Revista de cultura digital. Monterrey: Instituto Tecnológico y de Estudios Superiores de Monterrey, Escuela de Humanidades y Educación, número 17 (2018), 36-54.

Caresani, Rodrigo y Günther Schmigalle

Bibliografia de Rubén Darío en La Nación de Buenos Aires (1889-1916). Catálogo comentado y crónicas desconocidas. Managua: Dinámica/Embajada de la República Argentina, 2017.

Colombi, Beatriz

"Peregrinaciones parisinas: Rubén Darío", en Orbis Tertius. La Plata: Universidad Nacional de La Plata, Facultad de Humanidades y Ciencias de la Educación, volumen II, número 4 (1997), 117-130.

DARÍO, Rubén

La vida de Rubén Darío escrita por él mismo. Barcelona: Maucci, 1915. 


\section{Rodrigo Javier Caresani}

Escritos inéditos. Edición de Erwin K. Mapes. Nueva York: Instituto de las Españas en los Estados Unidos, 1938.

Escritos dispersos de Rubén Darío. Edición de Pedro Luis Barcia. La Plata: Universidad Nacional de La Plata, Facultad de Humanidades y Ciencias de la Educación, 1968-1977, 2 volúmenes.

Páginas desconocidas de Rubén Darío. Edición de Roberto Ibáñez. Montevideo: Biblioteca de Marcha, 1970.

Crónicas desconocidas, 1901-1906. Edición de Günther Schmigalle. Managua/Berlín: Academia Nicaragüense de la Lengua/Tranvía, 2006.

Crónicas desconocidas, 1906-1914. Edición de Günther Schmigalle. Managua: Academia Nicaragüense de la Lengua, 2011 a.

La República de Panamá y otras crónicas desconocidas. Selección, estudios y notas de Jorge Eduardo Arellano. Managua: Academia Nicaragüense de la Lengua, $2011 \mathrm{~b}$.

La caravana pasa. Edición de Günther Schmigalle. Sáenz Peña: Universidad Nacional de Tres de Febrero, 2019.

FARKas, Mónica

"V. Colección Carlés I y II", en Laura Malosetti Costa (editora). Entresiglos. El impulso cosmopolita en Rosario. Rosario: Castagnino/Macro, 2013, 45-67.

FERnÁNDEZ, Teodosio

"Rubén Darío en la AECID: correspondencia de Leonidas Pallares y Leopoldo Díaz", en Anales de Literatura Hispanoamericana. Madrid: Universidad Complutense de Madrid, número 46 (2017), 217-231.

Fuente Ballesteros, Ricardo de la y Francisco Estévez

“Editar a Rubén Darío”, en Ínsula, número 838 (2016), 15-18.

García Morales, Alfonso

"Construyendo el modernismo hispanoamericano: Rubén Darío y Carlos Romagosa", en Alfonso García Morales (editor). Rubén Darío. Estudios en el centenario de Los raros y Prosas profanas. Sevilla: Secretariado de Publicaciones de la Universidad de Sevilla, 1998, 85-1 14.

García Soriano, Manuel

El periodismo tucumano, 1817-1900. Ensayo de investigación sobre un aspecto de la cultura de Tucumán durante el siglo XIX. Tucumán: Universidad Nacional de Tucumán, 1972.

González Stephan, Beatriz y Jens Andermann

Galerías del progreso. Museos, exposiciones y cultura visual en América Latina. Rosario: Beatriz Viterbo, 2006.

128 (an)ecdótica * vol. V, núm. 1, enero-junio 2021 


\section{Dos textos desconocidos de Rubén Darío en El Orden de Tucumán}

Gubernatis, Angelo de

Dizionario degli artisti italiani viventi. Pittori, scultori e architetti. Firenze: Le Monnier, 1889.

Jáuregui, Carlos

“Calibán, ícono del 98. A propósito de un artículo de Rubén Darío", en Revista Iberoamericana. Pittsburgh: University of Pittsburgh, volumen LXIV, números 184-185 (1998), 441-449.

KAPLAN, Michel

"Impresiones artísticas", en El Mercurio de América. Buenos Aires, año I, tomo I, número 6 (1898), 331-334.

Ramos, Julio

Desencuentros de la modernidad en América Latina. México: Fondo de Cultura Económica, 1989.

Risco, Ana María

"Canto y desencanto del cisne. Rubén Darío en el diario El Orden de Tucumán (Argentina, 1898)", en Anales de Literatura Española. Alicante: Universidad de Alicante, Área de Literatura Española, Departamento de Filología Española, número 26 (2014) 363-392.

Rivas Bravo, Noel

"Breve recorrido por las ediciones darianas", en Anales de Literatura Hispanoamericana. Madrid: Universidad Complutense de Madrid, número 35 (2006), 13-20.

SÁnchez Andrés, Agustín

"La normalización de las relaciones entre España y Centroamérica durante la gestión de Julio de Arellano y Arróspide (1889-1895)", en Revista Complutense de Historia de América, volumen 42 (2016), 243-266.

Siskind, Mariano

Deseos cosmopolitas. Modernidad global y literatura mundial en América Latina. Buenos Aires: Fondo de Cultura Económica, 2016.

WARren, Michelle

"Post-philology", en Patricia Clare Ingham y Michelle Warren (editors). Postcolonial Moves. Medieval through Modern. New York: Palgrave, 2003, 19-45.

"Relating Philology: Practicing Humanism", en PMLA. New York: Modern Language Association, volumen 125, número 2 (2010), 283-288.

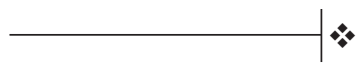

